Article

\title{
Microbial Oxidation of the Fusidic Acid Side Chain by Cunninghamella echinulata
}

\author{
Abdel-Rahim S. Ibrahim ${ }^{1}$, Khaled M. Elokely ${ }^{2,3}$, Daneel Ferreira ${ }^{4}$ and Amany E. Ragab ${ }^{1, *}$ \\ 1 Department of Pharmacognosy, Faculty of Pharmacy, Tanta University, Tanta 31527, Egypt; \\ arsib16@hotmail.com \\ 2 Department of Pharmaceutical Chemistry, Faculty of Pharmacy, Tanta University, Tanta 31527, Egypt; \\ kelokely@pharm.tanta.edu.eg \\ 3 Institute for Computational Molecular Science and Department of Chemistry, Temple University, \\ Philadelphia, PA 19122, USA \\ 4 Department of BioMolecular Sciences, Division of Pharmacognosy, School of Pharmacy, \\ The University of Mississippi, University, MS 38677-1848, USA; dferreir@olemiss.edu \\ * Correspondence: amany.ragab@pharm.tanta.edu.eg; Tel.: + 20-403-336-007 (ext. 266)
}

Academic Editor: Charles L. Cantrell

Received: 10 April 2018; Accepted: 20 April 2018; Published: 21 April 2018

\begin{abstract}
Biotransformation of fusidic acid (1) was accomplished using a battery of microorganisms including Cunninghamella echinulata NRRL 1382, which converted fusidic acid (1) into three new metabolites 2-4 and the known metabolite 5 . These metabolites were identified using 1D and 2D NMR and HRESI-FTMS data. Structural assignment of the compounds was supported via computation of ${ }^{1} \mathrm{H}$ - and ${ }^{13} \mathrm{C}$-NMR chemical shifts. Compounds 2 and $\mathbf{3}$ were assigned as the 27-hydroxy and 26-hydroxy derivatives of fusidic acid, respectively. Subsequent oxidation of 3 afforded aldehyde 4 and the dicarboxylic acid 5. Compounds 2, 4 and 5 were screened for antimicrobial activity against different Gram positive and negative bacteria, Mycobacterium smegmatis, M. intercellulare and Candida albicans. The compounds showed lower activity compared to fusidic acid against the tested strains. Molecular docking studies were carried out to assist the structural assignments and predict the binding modes of the metabolites.
\end{abstract}

Keywords: fusidic acid; Cunninghamella echinulata; C-26-oxidation; C-27-oxidation

\section{Introduction}

Fusidic acid (1) is a natural antibacterial steroid-like compound without any steroidal activity [1,2]. It was first isolated and identified from the fungus Fusidium coccineum [1,2] and introduced into the market in the 1960s as the corresponding sodium salt for clinical use. It has activity against Gram positive bacteria, particularly methicillin resistant Staphylococcus aureus (MRSA), and modest activity against anaerobic Gram-negative bacteria [3,4]. Fusidic acid (1) acts through inhibition of protein synthesis by binding to the elongation factor EF-G [5]. The specific and narrow spectrum of activity of fusidic acid makes it an ideal target for investigating possible biotransformation pathways and the effects of the metabolites on the activity spectrum and/or efficacy. Here, we explored the metabolic fate of fusidic acid using several organisms among which the fungus Cunninghamella echinulata was the most proficient in the biotransformation of this antibiotic.

Fusidic acid (Figure 1) is metabolized into a dicarboxylic acid derivative in mammals. Other detected metabolites include 3-didehydrofusidic acid and fusidic acid 21-O-glucuronide conjugate [6,7]. Fusidic acid was reported to undergo oxygenation and oxidation by microbial transformation to yield 6-hydroxy, 7-hydroxy, 3-didehydro and 6-oxofusidic acid [8-10] or deacetylation to produce the $16 \beta$-hydroxy derivative, which spontaneously converts into the biologically inactive lactone analog [11]. 
16-De-O-acetyl-7 $\beta$-hydroxyfusidic acid was isolated from the fungus Acremonium crotocinigenum [12]. Biotransformation of the side chain functionalities of fusidic acid is rare. Several microbial strains were harnessed for studying the metabolism of drugs as a mimic of the phase- 1 mammalian metabolism stage [13]. Cunninghamella echinulata is one of the established microbial models for investigating bioconversions of xenobiotics [13]. This study describes the formation of new metabolites emanating from microbial transformation of the side chain functionalities of fusidic acid using C. echinulata.

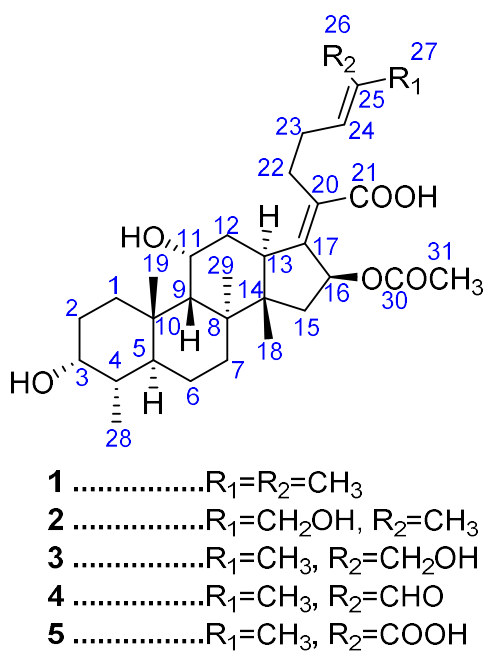

Figure 1. Structures of fusidic acid (1) and the isolated metabolites.

\section{Results and Discussion}

Compound 2 (Figure 1) showed a potassium adduct ion at $m / z 571.3030$ using high resolution electrospray ionization Fourier transform mass spectrometry (HRESI-FTMS) which, in conjunction with the ${ }^{1} \mathrm{H}$ - and ${ }^{13} \mathrm{C}-\mathrm{NMR}$ data (Tables 1 and 2), corresponds to a molecular formula of $\left[\mathrm{C}_{31} \mathrm{H}_{48} \mathrm{O}_{7}+\mathrm{K}^{+}\right.$ (calculated 571.3032). The molecular formula of fusidic acid is $\mathrm{C}_{31} \mathrm{H}_{48} \mathrm{O}_{6}$ and the observed molecular formula of 2 thus indicates the mono-oxygenation of fusidic acid. By comparison of the ${ }^{13} \mathrm{C}-\mathrm{NMR}$ data of fusidic acid and compound 2, C-27 was deshielded from $\delta_{\mathrm{C}} 25.7$ to 68.6 suggesting its conversion from $\mathrm{CH}_{3}$ to $\mathrm{CH}_{2}-\mathrm{O}$-, and thus resulted in deshielding of $\mathrm{C}-25$ and shielding of $\mathrm{C}-26$ (Table 2). The DEPT 135 experiment showed nine methylene carbons compared to the eight of fusidic acid. The ${ }^{1} \mathrm{H}-\mathrm{NMR}$ spectrum of compound 2 in $\mathrm{CDCl}_{3}$ (Table 1) showed the presence of a singlet at $\delta_{\mathrm{H}} 3.9$ integrating for two protons with the absence of the singlet at $\delta_{\mathrm{H}} 1.67$ for Me-27 in the spectrum of fusidic acid. This shift is consistent with a methylene group carrying an electronegative atom, thus, indicating the structure of compound 2 as 27-hydroxyfusidic acid. Other proton and carbon signals were highly similar to those of fusidic acid (Tables 1 and 2). The 2D HSQC NMR spectrum showed correlation of the proton singlet of $\mathrm{CH}_{2}-27\left(\delta_{\mathrm{H}} 3.9\right)$ and $\mathrm{C}-27$ at $\delta_{\mathrm{C}} 68.6$ which confirmed the site of oxygenation in compound 2 at C-27 (Figure 1). The ${ }^{1} \mathrm{H}^{-1} \mathrm{H}$ COSY spectrum of fusidic acid (Supplementary Materials) indicated the correlation of the protons at C-24 and C-27 which disappeared in the ${ }^{1} \mathrm{H}-{ }^{1} \mathrm{H}$ COSY spectrum of compound 2 suggesting that compound 2 is a $(24 E)$ isomer. The experimental and computed chemical shifts of compound 2 were compared to assign the degree of fitness (Supplementary Materials), using the mean absolute error (MAE) and regression analysis $\left(\mathrm{R}^{2}\right)$ for that purpose. The absolute error for the computed ${ }^{13} \mathrm{C}-\mathrm{NMR}$ data of 2 was calculated as 68.14 and the MAE as 2.198 supporting the assignment of 2 as the (24E) geometrical isomer of the new 27-hydroxyfusidic acid. 
Table 1. ${ }^{1} \mathrm{H}-\mathrm{NMR}$ data of fusidic acid and the isolated metabolites. $\delta_{\mathrm{H}} \mathrm{ppm}(J=\mathrm{Hz})$.

\begin{tabular}{|c|c|c|c|c|c|}
\hline \multirow{2}{*}{ Position } & \multicolumn{5}{|c|}{ Compound } \\
\hline & $1 *$ & $2(300 \mathrm{MHz})$ & 3 (500 MHz) & $4(300 \mathrm{MHz})$ & 5 (500 MHz) \\
\hline 1 & $1.51(\mathrm{~m}) / 2.17(\mathrm{~m})$ & $1.49(\mathrm{~m}) / 2.07(\mathrm{~m})$ & $1.50(\mathrm{~m}) / 2.09(\mathrm{~m})$ & $1.50(\mathrm{~m}) / 2.09(\mathrm{~m})$ & $1.51(\mathrm{~m}) / 2.17(\mathrm{~m})$ \\
\hline 2 & $1.75(\mathrm{~m}) / 1.86(\mathrm{~m})$ & $1.71(\mathrm{~m}) / 1.82(\mathrm{~m})$ & $1.63(\mathrm{~m})$ & $1.70(\mathrm{~m}) / 1.83(\mathrm{~m})$ & $1.62(\mathrm{~m}) / 1.88(\mathrm{~m})$ \\
\hline 3 & $3.76(\mathrm{~s})$ & $3.72(\mathrm{~s})$ & $3.73(\mathrm{~s})$ & $3.75(\mathrm{~d}, 1.54)$ & $3.68(\mathrm{~s})$ \\
\hline 4 & $1.58(\mathrm{~m})$ & 1.46 (brs) & $1.51(\mathrm{~m})$ & $1.46(\mathrm{~m})$ & $1.55(\mathrm{~m})$ \\
\hline 5 & $2.11(\mathrm{~m})$ & $2.17(\mathrm{~m})$ & $2.17(\mathrm{~m})$ & $2.10(\mathrm{~m})$ & $2.17(\mathrm{~m})$ \\
\hline 6 & $1.13(\mathrm{~m}) / 1.59(\mathrm{~m})$ & $1.09(\mathrm{~m}) / 1.60(\mathrm{~m})$ & $1.12(\mathrm{~m}) / 1.60(\mathrm{~m})$ & $1.11(\mathrm{~m}) / 1.70(\mathrm{~m})$ & $1.16(\mathrm{~m}) / 1.73(\mathrm{~m})$ \\
\hline 7 & $1.12(\mathrm{~m}) / 1.74(\mathrm{~m})$ & $1.68(\mathrm{~m}) / 1.11(\mathrm{~m})$ & $1.68(\mathrm{~m}) / 1.12(\mathrm{~m})$ & $1.24(\mathrm{~m}) / 1.83(\mathrm{~m})$ & $1.16(\mathrm{~m}) / 1.8(\mathrm{~m})$ \\
\hline 8 & - & - & - & - & - \\
\hline 9 & $1.57(\mathrm{~s})$ & $1.55(\mathrm{~s})$ & $1.59(\mathrm{~s})$ & $1.56(\mathrm{~s})$ & $1.62(\mathrm{~s})$ \\
\hline 10 & - & - & - & - & - \\
\hline 11 & 4.35 (brs) & $4.36(\mathrm{brs})$ & 4.36 (brs) & 4.34 (brs) & 4.34 (brs) \\
\hline 12 & $1.85(\mathrm{~m}) / 2.33(\mathrm{~m})$ & $1.82(\mathrm{~m}) / 2.44(\mathrm{~m})$ & $2.44(\mathrm{~m})$ & $1.87(\mathrm{~m}) / 2.43(\mathrm{~m})$ & $1.89(\mathrm{~m}) / 2.32(\mathrm{~m})$ \\
\hline 13 & $3.06(\mathrm{~d}, 10.91)$ & $2.95(\mathrm{~d}, 13.0)$ & $3.06(\mathrm{~d}, 10.66)$ & $3.08(\mathrm{~d}, 11.10)$ & $3.11(\mathrm{~d}, 11.20)$ \\
\hline 14 & - & - & - & - & - \\
\hline 15 & $1.30(\mathrm{~d}, 14.20) / 2.19(\mathrm{~m})$ & $1.27(\mathrm{~d}, 14.0) / 2.17(\mathrm{~m})$ & $1.27(\mathrm{~m}) / 2.19(\mathrm{~m})$ & $2.10(\mathrm{~m}) / 1.40(\mathrm{~m})$ & $1.27(\mathrm{~d}, 4.20) / 2.18(\mathrm{~m})$ \\
\hline 16 & $5.88(\mathrm{~d}, 8.32)$ & $5.88(\mathrm{~d}, 8.2)$ & $5.86(\mathrm{~d}, 7.02)$ & $5.90(\mathrm{~d}, 8.3)$ & $5.85(\mathrm{~d}, 8.17)$ \\
\hline 17 & - & - & - & - & - \\
\hline 18 & $0.89(\mathrm{~s})$ & $0.88(\mathrm{~s})$ & $0.91(\mathrm{~s})$ & $0.91(\mathrm{~s})$ & $0.96(\mathrm{~s})$ \\
\hline 19 & $0.96(\mathrm{~s})$ & $0.96(\mathrm{~s})$ & $0.98(\mathrm{~s})$ & $0.96(\mathrm{~s})$ & $1.02(\mathrm{~s})$ \\
\hline 20 & - & - & - & - & - \\
\hline 21 & - & - & - & - & - \\
\hline 22 & $2.46(\mathrm{~m})$ & $2.55(\mathrm{~m})$ & $2.55(\mathrm{~m})$ & $2.43(\mathrm{~m}) / 2.61(\mathrm{~m})$ & $2.57(\mathrm{~m}) / 2.65(\mathrm{~m})$ \\
\hline 23 & $2.07(\mathrm{~m}) / 2.17(\mathrm{~m})$ & $2.05(\mathrm{~m}) / 2.20(\mathrm{~m})$ & $2.30(\mathrm{~m})$ & $2.61(\mathrm{~m})$ & $2.33(\mathrm{~m})$ \\
\hline 24 & $5.10(\mathrm{t}, 6.97)$ & $4.49(\mathrm{t}, 7.2)$ & $5.26(t, 7.2)$ & $6.49(t, 7.9)$ & $6.80(t, 8.0)$ \\
\hline 25 & - & - & - & - & - \\
\hline 26 & $1.60(\mathrm{~s})$ & $1.62(\mathrm{~s})$ & $\begin{array}{l}4.03(\mathrm{~d}, 11.75) \\
4.13(\mathrm{~d}, 11.75)\end{array}$ & $9.36(\mathrm{~s})$ & - \\
\hline 27 & $1.67(\mathrm{~s})$ & $3.9(\mathrm{~s})$ & $1.77(\mathrm{~s})$ & $1.73(\mathrm{~s})$ & $1.84(\mathrm{~s})$ \\
\hline 28 & $0.90(\mathrm{~d}, 5.8)$ & $0.89(\mathrm{~d}, 7.8)$ & $0.90(\mathrm{~d}, 7.28)$ & $0.90(\mathrm{~d}, 6.31)$ & $0.92(\mathrm{~d}, 6.43)$ \\
\hline 29 & $1.38(\mathrm{~s})$ & $1.34(\mathrm{~s})$ & $1.38(\mathrm{~s})$ & $1.36(\mathrm{~s})$ & $1.41(\mathrm{~s})$ \\
\hline 31 & $1.96(\mathrm{~s})$ & $1.97(\mathrm{~s})$ & $1.99(\mathrm{~s})$ & $1.96(\mathrm{~s})$ & $1.98(\mathrm{~s})$ \\
\hline
\end{tabular}

* Data of fusidic acid (1) taken from reference [14].

The HRESI-FTMS data of compound 3 showed a potassium adduct ion at $m / z 571.3030$ which, in conjunction with ${ }^{13} \mathrm{C}$-NMR data, corresponds to a molecular formula of $\left[\mathrm{C}_{31} \mathrm{H}_{48} \mathrm{O}_{7}+\mathrm{K}\right]^{+}$(calculated 571.3032) suggesting the oxygenation of fusidic acid. Comparing the ${ }^{13} \mathrm{C}-\mathrm{NMR}$ data of fusidic acid and compound 3, C-26 was deshielded from $\delta_{C} 17.8$ to 61.2 which resulted in deshielding of C-24, C-25 and shielding of C-27 (Table 2). The DEPT 135 spectrum showed nine methylene carbons with the chemical shift of the carbon at $\delta_{C} 61.2$ suggesting oxygenation at C-26. The ${ }^{1} \mathrm{H}-\mathrm{NMR}$ data of compound 3 in $\mathrm{CDCl}_{3}$ showed two doublets at $\delta_{\mathrm{H}} 4.03$ and $4.13\left({ }^{3} \mathrm{~J}=11.75 \mathrm{~Hz}\right)$, characteristic for geminal coupling, replacing the singlet $\left(\delta_{\mathrm{H}} 1.60\right)$ for Me-26 in the spectrum of fusidic acid. This shift is reminiscent of a methylene group attached to an electronegative atom suggesting the structure of compound 3 as 26-hydroxyfusidic acid. Other proton and carbon signals were similar to those of fusidic acid (Tables 1 and 2). The gradient HMQC data showed correlation of the proton doublets at $\delta_{\mathrm{H}} 4.03$ and 4.13 and $C-26\left(\delta_{C} 61.2\right)$ which confirmed the site of oxygenation in compound 3 at C-26 (Figure 1). The ${ }^{1} \mathrm{H}-{ }^{1} \mathrm{H}$ COSY spectrum showed the correlation of the protons at $\mathrm{C}-24$ and $\mathrm{C}-27$, indicating that compound 3 is a (24Z) isomer. The computed ${ }^{13} \mathrm{C}-\mathrm{NMR}$ spectrum of 3 showed an absolute error of 83.157 with an MAE of 2.682 matching the assignment of the structure of compound 3 as the new (24Z)-26-hydroxyfusidic acid. 
Table 2. ${ }^{13} \mathrm{C}-\mathrm{NMR}$ data of fusidic acid and the isolated metabolites. $\delta_{\mathrm{C}} \mathrm{ppm}$.

\begin{tabular}{|c|c|c|c|c|c|}
\hline \multirow{2}{*}{ Position } & \multicolumn{5}{|c|}{ Compound } \\
\hline & $1 *$ & 2 (75 MHz) & 3 (125 MHz) & 4 (75 MHz) & 5 (125 MHz) \\
\hline 1 & 30.2 & 30.1 & 30.2 & 30.5 & 31.4 \\
\hline 2 & 29.8 & 30.4 & 30.1 & 30.2 & 31.4 \\
\hline 3 & 71.5 & 71.9 & 72.0 & 71.9 & 72.9 \\
\hline 4 & 36.4 & 36.1 & 35.7 & 36.7 & 38.6 \\
\hline 5 & 36.0 & 37.1 & 37.2 & 36.3 & 37.2 \\
\hline 6 & 20.9 & 21.4 & 23.0 & 21.2 & 22.8 \\
\hline 7 & 32.1 & 32.1 & 32.0 & 31.9 & 33.3 \\
\hline 8 & 39.5 & 49.1 & 39.9 & 39.3 & 41.1 \\
\hline 9 & 49.3 & 50.0 & 49.8 & 49.7 & 51.1 \\
\hline 10 & 36.9 & 39.8 & 36.9 & 37.3 & 38.2 \\
\hline 11 & 68.2 & 69.0 & 68.5 & 68.5 & 69.0 \\
\hline 12 & 35.6 & 35.5 & 35.7 & 36.0 & 37.8 \\
\hline 13 & 44.3 & 44.7 & 44.5 & 44.9 & 45.6 \\
\hline 14 & 48.7 & 49.1 & 49.2 & 49.2 & 50.4 \\
\hline 15 & 38.9 & 39.2 & 39.3 & 39.3 & 40.4 \\
\hline 16 & 74.5 & 74.9 & 74.9 & 74.8 & 76.1 \\
\hline 17 & 150.7 & 150.2 & 150.4 & 152.8 & 150.6 \\
\hline 18 & 17.8 & 18.0 & 18.0 & 18.3 & 18.5 \\
\hline 19 & 23.0 & 23.7 & 23.6 & 23.4 & 24.2 \\
\hline 20 & 129.6 & 129.9 & 130.2 & 128.8 & 131.6 \\
\hline 21 & 174.4 & 173.9 & 173.2 & 173.2 & 174.0 \\
\hline 22 & 28.8 & 27.2 & 28.1 & 29.6 & 29.0 \\
\hline 23 & 28.5 & 27.9 & 28.8 & 27.7 & 30.3 \\
\hline 24 & 123.1 & 124.0 & 127.1 & 152.2 & 142.5 \\
\hline 25 & 132.6 & 136.2 & 135.6 & 140.3 & 130.2 \\
\hline 26 & 17.8 & 14.1 & 61.2 & 195.8 & 172.9 \\
\hline 27 & 25.7 & 68.6 & 21.8 & 9.6 & 13.0 \\
\hline 28 & 15.9 & 16.3 & 16.3 & 16.3 & 16.9 \\
\hline 29 & 23.9 & 24.1 & 24.0 & 24.3 & 24.0 \\
\hline 30 & 170.7 & 171.4 & 171.6 & 171.2 & 172.0 \\
\hline 31 & 20.6 & 21.0 & 21.0 & 21.0 & 21.1 \\
\hline
\end{tabular}

We next investigated the phenomenon of the 27-hydroxymethylene protons in $\mathbf{2}$ resonating as a singlet and the 26-hydroxymethylene protons in 3 as two one-proton doublets. The lowest energy conformers were analyzed to investigate the relative chemical environment of these protons in each case (Figure 2). Owing to strong hydrogen bonding between the C-11 and C-27 hydroxy groups, two major orientations of the C-27 protons of compound 2 were observed (Figure 2, panels A and B). This creates similar average chemical environments and results in a singlet resonance for the geminal hydrogen atoms. In 3, the hydrogen bonding between the C-11 and C-26 hydroxy groups anchored the C-26 methylene (Figure 2, panel C) group to such an extent as to create diastereotopic-like protons culminating in two one-proton doublets in the ${ }^{1} \mathrm{H}-\mathrm{NMR}$ spectrum.

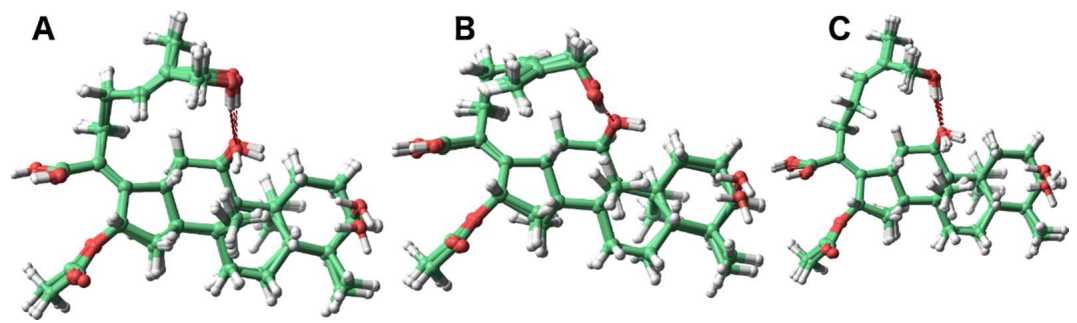

Figure 2. The most abundant conformers of $\mathbf{2}(\mathbf{A}$ and $\mathbf{B})$ and $\mathbf{3}(\mathbf{C})$.

The HRESI-FTMS data of compound 4 revealed a sodium adduct ion at $m / z 553.3131$ which, in conjunction with the ${ }^{13} \mathrm{C}-\mathrm{NMR}$ data, accounts for a molecular formula of $\left[\mathrm{C}_{31} \mathrm{H}_{46} \mathrm{O}_{7}+\mathrm{Na}\right]^{+}$ 
(calculated 553.3135), again indicative of the presence of an oxidation product of fusidic acid. By comparison of the ${ }^{13} \mathrm{C}-\mathrm{NMR}$ data of fusidic acid and compound 4, C-26 was deshielded from $\delta_{C} 17.8$ to 195.8 indicating the oxidation of Me-26 into a formyl group which resulted in deshielding of C-24, C-25 and shielding of C-27 (Table 2). The DEPT 90 spectrum of compound 4 showed nine methine carbons in contrast to the eight of fusidic acid. The ${ }^{1} \mathrm{H}-\mathrm{NMR}$ data of compound 4 in $\mathrm{CDCl}_{3}$ showed the presence of a one-proton singlet at $\delta_{\mathrm{H}} 9.36$ and the absence of the Me-26 singlet $\left(\delta_{\mathrm{H}} 1.60\right)$ in the spectrum of fusidic acid. This shift is reminiscent of formyl group formation suggesting the structure of compound 4 as 26-formylfusidic acid. The HSQC spectrum showed correlation of the proton singlet $\left(\delta_{\mathrm{H}} 9.36\right)$ and $\mathrm{C}-26\left(\delta_{\mathrm{C}} 195.8\right)$, and, thus, confirmed the structure of the new compound 4 (Figure 1$)$. The ${ }^{1} \mathrm{H}-{ }^{1} \mathrm{H}$ COSY spectrum showed the correlation of the protons at C-24 and C-27, indicating that compound 4 is a $(24 Z)$ isomer. The calculated absolute error, MAE and $\left(R^{2}\right)$ supported the structural assignment of the new compound 4 as (24Z)-26-formylfusidic acid (Supplementary Materials).

The molecular formula of compound 5 was determined as $\mathrm{C}_{31} \mathrm{H}_{46} \mathrm{O}_{8}$ via its ${ }^{13} \mathrm{C}-\mathrm{NMR}$ and HRESI-FTMS data which showed a sodium adduct ion at $m / z 569.3072$ for $\left[\mathrm{C}_{31} \mathrm{H}_{46} \mathrm{O}_{8}+\mathrm{Na}^{+}\right.$ (calculated 569.3084). The molecular formula of compound 5 has one extra oxygen atom compared to compound 4 which is reminiscent of an oxidation product of fusidic acid. By comparison of the ${ }^{13} \mathrm{C}-\mathrm{NMR}$ data of fusidic acid and compound 5, the C-26 resonance was deshielded from $\delta_{\mathrm{C}} 17.8$ to 172.9 which strongly suggests oxidation at C-26, thus resulted in deshielding of C-24, C-25 and shielding of C-27 (Table 2). The DEPT 90 and 135 spectra of compound 5 evidenced one fewer methyl group compared to fusidic acid which implied the presence of a hydroxycarbonyl functional group. The ${ }^{1} \mathrm{H}-\mathrm{NMR}$ data of compound 5 in methanol- $d_{4}$ showed the disappearance of the Me-26 singlet $\left(\delta_{\mathrm{H}} 1.60\right)$ present in the spectrum of fusidic acid. This is consistent with the presence of a carboxylic group, and hence the structure of compound $\mathbf{5}$ as 26-carboxyfusidic acid (Figure 1) which matched the literature data [7]. 2D NMR data of compound 5 supported the deduced structure.

Compounds 3 and 4 may be considered as intermediates towards the formation of compound 5 and this is the first report of their formation and structural elucidation. Von Daehne et al. reported as "unpublished observations" that compound 2 was chemically synthesized by Godtfredsen and Vangedal via oxidation of fusidic acid with selenium oxide in $t$-butanol [14], followed by reduction with sodium borohydride to yield compound 2 . The oxygenation step of the 26-Me and 27-Me diastereotopic ligands in the side chain of fusidic acid using C. echinulata does not exhibit regioselectivity, whereas subsequent oxidation of the mixture of $\mathbf{2}$ and $\mathbf{3}$ into the formyl and hydroxycarbonyl fusidic acid derivatives 4 and 5 proceeded regiospecifically at C-26.

The antimicrobial activity testing of compounds 2, 4 and 5 revealed that oxidation of fusidic acid at C-26 to the formyl derivative 4 diminishes the activity, whilst further oxidation to the carboxylic acid 5 abolishes the activity completely. The oxygenation at C-27 decreased the antimicrobial activity of fusidic acid (Table 3). These results showed that the methyl groups in the side chain of fusidic acid are crucial for maximum activity.

Table 3. Antimicrobial activity testing of fusidic acid and the isolated metabolites.

\begin{tabular}{ccccc}
\hline \multirow{2}{*}{ Microorganism } & \multicolumn{4}{c}{ Compound, MIC $(\boldsymbol{\mu g} / \mathbf{m L})$} \\
\cline { 2 - 5 } & Fusidic acid 1 & $\mathbf{2}$ & $\mathbf{4}$ & $\mathbf{5}$ \\
\hline Streptomyces faecalis & 1.50 & 50 & 50 & -ve * \\
Streptomyces durans & 6.00 & 25 & 25 & -ve \\
Staphyllococcus aureus & 0.38 & 2.5 & 2.5 & -ve \\
Bacillus subtlis & 0.38 & 100 & 50 & -ve \\
Escherichia coli & $-\mathrm{ve}$ & $-\mathrm{ve}$ & -ve & -ve \\
Pseudomonas aeruginosa & $-\mathrm{ve}$ & $-\mathrm{ve}$ & -ve & -ve \\
Mycobacterium smegmatis & 12.5 & 100 & -ve & -ve \\
Mycobacterium intercellulare & 12 & -ve & -ve & -ve \\
Candida albicans & 1.25 & -ve & -ve & -ve \\
\hline -ve (no antimicrobial activity) at the highest tested concentration $(100 \mu \mathrm{\mu g} / \mathrm{mL})$.
\end{tabular}


A docking simulation was carried out using the crystal structure of Thermus thermophilus EF-G (PDB accession code: 4V5F). Fusidic acid showed the best docking score of $-4 \mathrm{kcal} / \mathrm{mol}$, while compounds $2,3,4$ and 5 exhibited docking scores of $-2.5,-2.6,-2.8$ and $-0.36 \mathrm{kcal} / \mathrm{mol}$, respectively. The simulated binding poses of compounds 2, 3 and 4 were studied and compared with that of fusidic acid (Figures 3-6). Compounds 1, 2, 3 and 4 exhibited non-covalent interactions with the amino acid residues of the ligand binding pocket, mostly in the form of electrostatic and Van der Waals contacts.
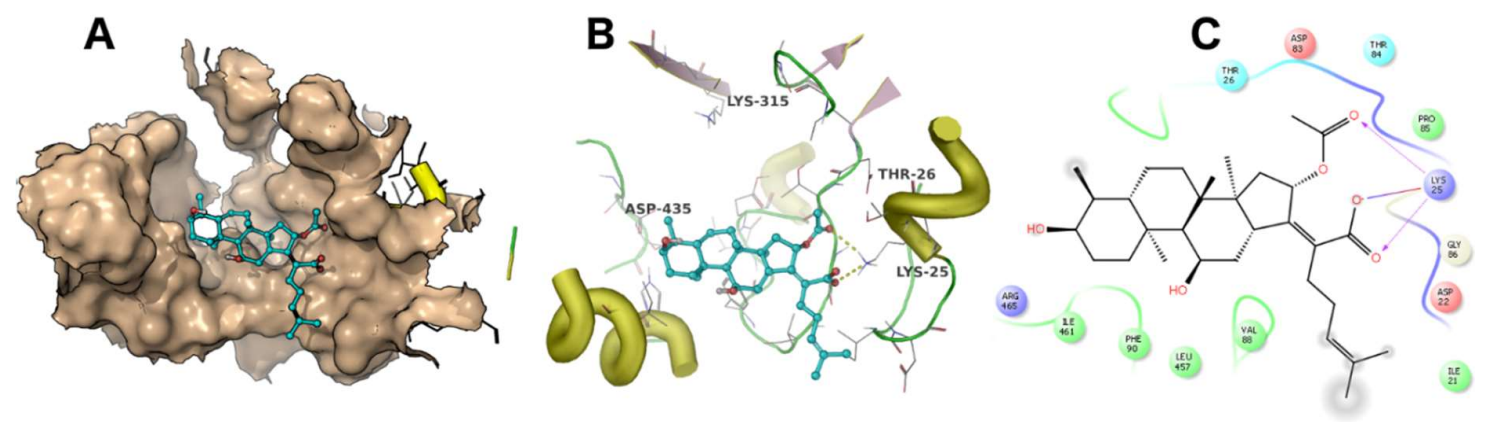

Figure 3. The binding mode of fusidic acid (1). The ligand binding pocket is shown as surface (A). The amino acid residues involved in ligand interaction are shown as lines (B). A 2D ligand interaction profile is demonstrated in (C).

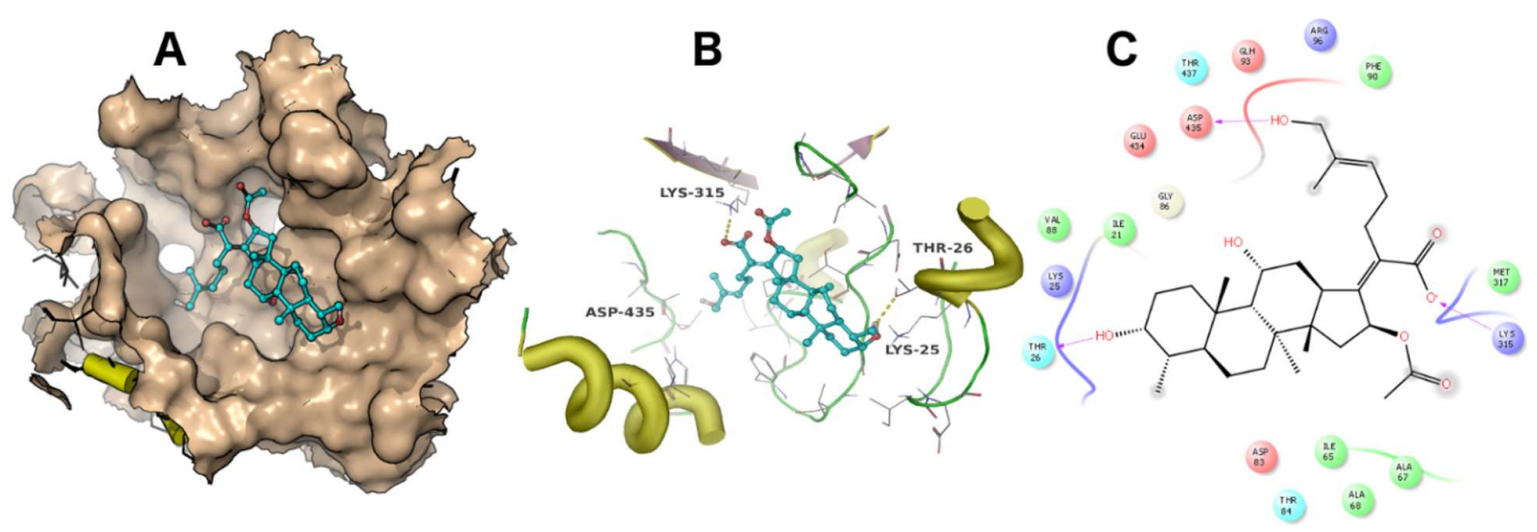

Figure 4. The binding mode of 2. The ligand binding pocket is shown as surface (A). The amino acid residues involved in ligand interaction are shown as lines (B). A 2D ligand interaction profile is demonstrated in $(\mathbf{C})$.
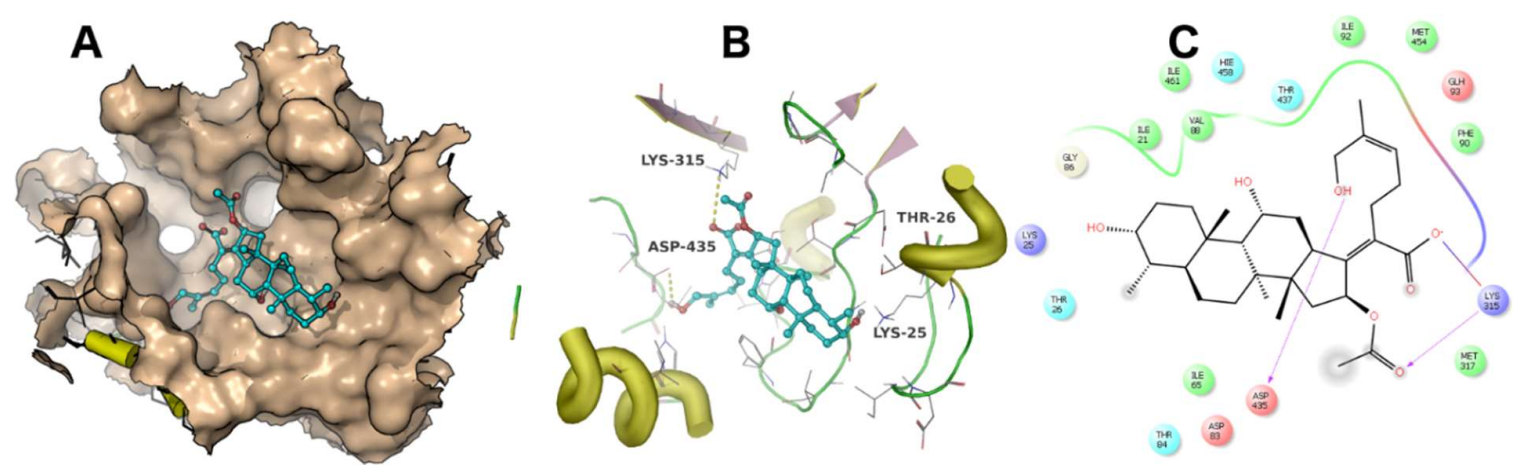

Figure 5. The binding mode of 3. The ligand binding pocket is shown as surface (A). The amino acid residues involved in ligand interaction are shown as lines (B). A 2D ligand interaction profile is demonstrated in (C). 

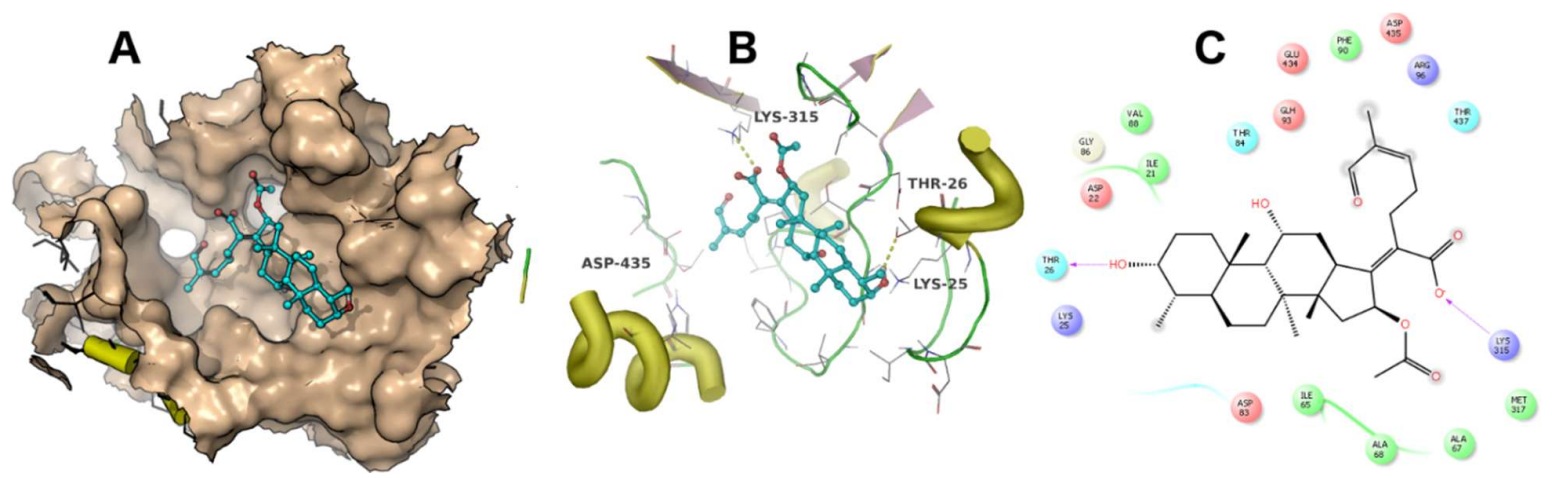

Figure 6. The binding mode of 4 . The ligand binding pocket is shown as surface (A). The amino acid residues involved in ligand interaction are shown as lines (B). A 2D ligand interaction profile is demonstrated in $(\mathbf{C})$.

The amino acid residues involved in ligand interaction include Thr26, Lys25, Ile21, Val88, Arg96, Asp435, Glu434, Met317, Lys315, Ala68, Ile65, Ala67, Asp83, Thr84, Thr437 and Phe90. Lys315 and Thr26 form conserved hydrogen bonds, while Asp435 forms a hydrogen bond only with 2. Lys25 showed a strong ionic interaction with 1 . This simulation indicated that fusidic acid fits best in the binding pocket with non-covalent and ionic interactions, while compounds $\mathbf{2}-\mathbf{4}$ showed less binding affinity which may account for their decreased activity. The docking score of compound 5 $(-0.36 \mathrm{kcal} / \mathrm{mol})$ implies weak or no binding which explains the complete loss of activity.

\section{Materials and Methods}

\subsection{General Experimental Procedures}

Sodium fusidate was purchased from Leo Pharmaceutical Company (Ballerup, Denmark). IR spectra were recorded on a Perkin Elmer IR spectrophotometer (PerkinElmer Inc., Waltham, MA, USA). UV data were acquired using a 60/PC ultraviolet spectrophotometer (Shimadzu, Kyoto, Japan). NMR spectra were recorded using Varian XL300 (Varian Inc., Palo Alto, CA, USA) and Bruker Avance 500 spectrophotometers (Bruker, Billerica, MA, USA) using $\mathrm{CDCl}_{3}$ and methanol- $d_{4}$ as solvents and tetramethyl silane (TMS) as internal standard. ${ }^{1} \mathrm{H}-\mathrm{NMR}$ spectra were recorded at 300 or $500 \mathrm{MHz}$, and ${ }^{13} \mathrm{C}-\mathrm{NMR}$ spectra at 75 or $125 \mathrm{MHz}$. DEPT, COSY and HETCOR analyses were obtained using Varian Pulse Sequences at 300 or $500 \mathrm{MHz}$. HR-ESIFTMS data were acquired using a Bruker Bioapex FT-mass spectrometer (Bruker, Billerica, MA, USA) in ESI mode. Thin layer chromatography (TLC) was carried out using precoated silica gel $60 \mathrm{~F}_{254}$ plates $(0.25 \mathrm{~mm}$ layer, E. Merck, Darmstadt, Germany) and visualization was by spraying with $p$-anisaldehyde reagent followed by heating at $110^{\circ} \mathrm{C}$.

\subsection{Preparation of Fusidic Acid}

Sodium fusidate was dissolved in water $(50 \mathrm{mg} / \mathrm{mL})$ and acidified with acetic acid. The precipitated fusidic acid was filtered, washed acid-free with distilled water, and dried to constant weight in a vacuum desiccator. The NMR and MS data were identical to reported data [14,15].

\subsection{Microorganisms and Culture Conditions}

Microbial transformation experiments were conducted according to published procedures [16]. For the initial screening experiments, 25 microbial cultures belonging to the genera Aspergillus, Candida, Cunninghamella, Saccharomyces, Rhizopus, Penicillium, Streptomyces, Gymnascella, Lindera, and Rhodotorula were used. The tested strains were obtained from either The American Type Culture Collection (ATCC, Manassas, VA, USA) or the National Center for Agricultural Utilization Research 
(NCAUR, Peoria, IL, USA). The strains were maintained at $4{ }^{\circ} \mathrm{C}$ on Sabouraud dextrose agar slants and subcultured quarterly.

\subsection{Culture Media}

In all fermentations, the medium consists of $10 \mathrm{~mL} / \mathrm{L}$ glycerol, $10 \mathrm{~g} / \mathrm{L}$ glucose, $5 \mathrm{~g} / \mathrm{L}$ peptone, $5 \mathrm{~g} / \mathrm{L}$ yeast extract, $5 \mathrm{~g} / \mathrm{L} \mathrm{NaCl}$, and $5 \mathrm{~g} / \mathrm{L} \mathrm{K}_{2} \mathrm{HPO}_{4}$ in distilled water. The $\mathrm{pH}$ was adjusted to 6.0 before autoclaving at $121^{\circ} \mathrm{C}$ for $15 \mathrm{~min}$.

\subsection{Initial Biotransformation Screening Experiments}

Cells of the tested microorganisms were transformed from two-week old slants into sterile liquid medium (50 mL/250 mL flask) and kept on a gyratory shaker at $28^{\circ} \mathrm{C}$ and $200 \mathrm{rpm}$ for $72 \mathrm{~h}$ to give stage I culture. Stage I culture $(5 \mathrm{~mL})$ was used as an inoculum for stage II culture $(50 \mathrm{~mL} / 250 \mathrm{~mL}$ flask). After $24 \mathrm{~h}$ of incubation of stage II culture, sodium fusidate $(10 \mathrm{mg})$ was added as a solution in absolute ethanol $(250 \mu \mathrm{L})$ to each flask. Samples were taken after 3 and 6 days of incubation, acidified with a few drops of $10 \% \mathrm{HCl}$, filtered and the filtrate was extracted with an equal volume of chloroform. After evaporation of the chloroform, the residues were chromatographed on precoated silica gel plates using chloroform-methanol (5:1) or benzene-ethyl acetate- formic acid (3 mL:7 mL:1 drop) as mobile phase and detection was carried out by UV light visualization and $p$-anisaldehyde spray reagent. Both substrate and organism-free controls were also prepared and processed in the same way. The results of preliminary screening using fusidic acid were identical to those of using sodium fusidate. Amongst the tested strains, C. echinulata NRRL 1382 and C. elegans 1392 displayed the best transformations. This paper discusses the metabolites obtained from transformation using C. echinulata.

\subsection{Large Scale Fermentation}

Stage I cultures were prepared by inoculating culture media with two weeks old Sabouraud dextrose agar slants of C. echinulata and incubated at $28^{\circ} \mathrm{C}$, and $200 \mathrm{rpm}$ for $72 \mathrm{~h}$. Stage II cultures were initiated by inoculating stage I culture $(5 \mathrm{~mL})$ into new culture media ( $50 \mathrm{~mL}$ in $250 \mathrm{~mL}$ flasks) and incubated at $28^{\circ} \mathrm{C}$, and $200 \mathrm{rpm}$ for $24 \mathrm{~h}$. Sodium fusidate, dissolved in absolute ethanol $(2.7 \mathrm{~g} / 67 \mathrm{~mL})$, was added to 270 stage II cultures to give a $0.02 \% w / v$ final concentration, and incubation continued for six days. Substrate and organism free control cultures were prepared. The cultures were pooled, acidified with $10 \% \mathrm{HCl}(1 \mathrm{~mL} / 30 \mathrm{~mL}$ culture), filtered and the filtrate was extracted twice with an equal volume of chloroform. The chloroform extract was dried over anhydrous sodium sulfate and evaporated under vacuum to give an amber-colored residue ( $3.4 \mathrm{~g}$ ). TLC was carried out using chloroform-methanol (5:1) or benzene-ethyl acetate-formic acid ( $3 \mathrm{~mL}: 7 \mathrm{~mL}: 1 \mathrm{drop}$ ) as mobile phases and detection was carried out by UV light visualization and $p$-anisaldehyde spray reagent.

\subsection{Isolation of Metabolites}

The residue obtained from the chloroform extract after evaporation ( $3.4 \mathrm{~g})$ was loaded onto a silica gel column $(300 \mathrm{~g})$ and eluted with a gradient of ethyl acetate in benzene $(0-60 \%)$ containing $0.2 \%$ formic acid and fractions of $100 \mathrm{~mL}$ were collected. The percentage of formic acid was increased to $0.4 \%$ starting from fraction no. 107 and similar fractions were pooled to give three groups of fractions.

\subsubsection{Fractions $80-106$}

The residue obtained upon pooling and evaporation of these fractions (360 $\mathrm{mg}$ ) was rechromatographed on a silica gel column (40 g) using a gradient of methanol/chloroform (0-10\%), and $50 \mathrm{~mL}$ fractions were collected. Fractions 47-64 afforded compound 4 (110 mg) and fractions 73-136 gave compound 5 (72 $\mathrm{mg})$. 


\subsubsection{Fractions $122-142$}

The residue of these fractions (300 mg) was rechromatographed on a silica gel column (40 g) using a gradient of methanol/chloroform (0-10\%) and $50 \mathrm{~mL}$ fractions were collected. Fractions 46-84 afforded compound 2 (115 mg).

\subsubsection{Fractions 143-190}

The residue of these fractions (320 mg) was partially purified using Sephadex LH-20 column (200 mL bed volume) chromatography followed by silica gel column chromatography (40 g) using a gradient of methanol/chloroform (0-4\%) and collecting $50 \mathrm{~mL}$ fractions. Fractions 79-114 yielded compound 3 which was recrystallized from n-hexane/chloroform mixture to provide $21 \mathrm{mg}$ of pure 3.

\subsubsection{7-Hydroxyfusidic Acid (2)}

White powder; UV (MeOH) $\lambda_{\max } 223 \mathrm{~nm}$; IR $v_{\max }\left(\mathrm{KBr}\right.$ disc) $\mathrm{cm}^{-1}$ : 3440, 2880, 1725, 1395, 1275; ${ }^{1} \mathrm{H}$ and ${ }^{13} \mathrm{C}-\mathrm{NMR}\left(\mathrm{CDCl}_{3}\right)$ : see Tables 1 and 2; HRESI-FTMS $(\mathrm{m} / \mathrm{z}): 571.3030[\mathrm{M}+\mathrm{K}]^{+}$(calc. for $\left.\mathrm{C}_{31} \mathrm{H}_{48} \mathrm{O}_{7} \mathrm{~K}, 571.3032\right)$.

\subsubsection{6-Hydroxyfusidic Acid (3)}

White powder; UV (MeOH) $\lambda_{\max } 223 \mathrm{~nm}$; IR $v_{\max }\left(\mathrm{KBr}\right.$ disc) $\mathrm{cm}^{-1}$ : 3432, 2936, 1717, 1638, 1443, 1379, 1260; ${ }^{1} \mathrm{H}$ and ${ }^{13} \mathrm{C}-\mathrm{NMR}\left(\mathrm{CDCl}_{3}\right)$ : see Tables 1 and 2; HRESI-FTMS $(\mathrm{m} / \mathrm{z}): 571.3030[\mathrm{M}+\mathrm{K}]^{+}$ (calc. for $\mathrm{C}_{31} \mathrm{H}_{48} \mathrm{O}_{7} \mathrm{~K}, 571.3032$ ).

\subsubsection{6-Formylfusidic Acid (4)}

White powder; UV (MeOH) $\lambda_{\max } 218 \mathrm{~nm}$; IR $v_{\max }\left(\mathrm{KBr}\right.$ disc) $\mathrm{cm}^{-1}$ : 3500, 2970, 2910, 1720, 1690, 1465, 1385, 1265; ${ }^{1} \mathrm{H}$ and ${ }^{13} \mathrm{C}-\mathrm{NMR}\left(\mathrm{CDCl}_{3}\right)$ : see Tables 1 and 2; $\operatorname{HRESI-FTMS~}(\mathrm{m} / z): 553.3131[\mathrm{M}+\mathrm{Na}]^{+}$ (calc. for $\mathrm{C}_{31} \mathrm{H}_{46} \mathrm{O}_{7} \mathrm{Na}, 553.3135$ ).

\subsubsection{6-Carboxyfusidic Acid (5)}

White powder; UV (MeOH) $\lambda_{\max } 223 \mathrm{~nm}$; IR $v_{\max }\left(\mathrm{KBr}\right.$ disc) $\mathrm{cm}^{-1}:$ 3435, 3169, 2939, 1700, 1641, 1381, 1260; ${ }^{1} \mathrm{H}$ and ${ }^{13} \mathrm{C}-\mathrm{NMR}\left(\mathrm{CDCl}_{3}\right)$ : see Tables 1 and 2 ; HRESI-FTMS $(\mathrm{m} / z): 569.3072[\mathrm{M}+\mathrm{Na}]^{+}$ (calc. for $\mathrm{C}_{31} \mathrm{H}_{46} \mathrm{O}_{8} \mathrm{Na}, 569.3084$ ).

\subsection{Antimicrobial Activity}

Samples were tested according to the National Committee of Clinical Laboratory Standard (NCCLS, 1994) using ATCC strains.

\subsection{Assignment of Relative Configuration}

To assign the relative configuration of the compounds, all possible chemical structures were sketched and energy minimized in Maestro. MacroModel with the OPLS3 forcefied was used to generate the conformers of the proposed structures. We used the stochastic conformational search approach of MacroModel and the Monte Carlo multiple minimum method to allow for better torsional sampling. The energy window for selecting the conformers was defined at $10.04 \mathrm{kcal} \mathrm{mol}^{-1}$. Geometry optimization and frequencies were calculated for all optimized conformers, based on Boltzmann analysis, using Gaussian 09 at the M06-2X/6-31+G(d,p) level. Gaussian 09 at the B3LYP/6-311+G(2d,p) level was used to compute the NMR shielding tensors using the gauge-independent (or including) atomic orbitals (GIAO) method. In all DFT calculations we used the integrated equation formalism polarized continuum model (IEFPCM) was used. 


\subsection{Protein Preparation}

The protein crystal structure of T. thermophilus EF-G (PDB accession code: 4V5F) was obtained from the protein databank (www.rcsb.org). The protein structure was prepared for docking by PrepWizard of the Schrödinger suite. Missing hydrogen atoms, amino acid side chains and loops were added. To account for correction of hydrogen bond networks, the orientations of amide groups (Asn and Gln), hydroxy groups (Tyr, Thr and Ser), and protonation states of imidazole moiety (His) were adjusted. No energy minimization was conducted.

\subsection{Ligand Preparation}

The compounds were sketched and converted into 3D structures in Maestro. The molecules were then prepared to address all possible protonation and tautomerization states using LigPrep with the OPLS3 forcefield. Only the lowest energy conformer for each ligand was kept.

\subsection{Receptor Grid Preparation}

The make receptor module of OpenEye scientific software (www.eyesopen.com) was used to construct the receptor grid. The native ligand was used to define the centroid of the docking box. The volume and dimensions of the grid box were defined as $7374 \AA^{3}(17.27 \AA \times 19.14 \AA \times 22.31 \AA)$. The dimensions of the outer contour of the docking region was $3140 \AA^{3}$.

\subsection{Docking Simulation}

The multi-conformers' compound database was docked using FRED of the OpenEye scientific software with standard docking precision was used. One best pose was saved for each compound.

\section{Conclusions}

Among the screened strains, C. echinulata was the only organism that metabolized fusidic acid (1) in a regioselective fashion targeting the allylic Me-26 and the Me-27 groups of the hydrophobic side chain. The microorganism seems to detoxify the antibiotic fusidic acid (1) by regioselective oxidation of the methyl groups of the hydrophobic side chain into hydroxymethyl, formyl and hydroxycarbonyl functionalities in order to minimize the antimicrobial activity. The dicarboxylic acid may eventually undergo decarboxylation to norfusidic acid, which, however is yet to be isolated and assessed for antimicrobial activity. The intermediate oxidation products $\mathbf{2}-\mathbf{4}$ may be exploited to develop antibiotic ligands with better activity and lower toxicity. These data indicate the presence of an interesting oxidation system in C. echinulata which targeted the side chain of fusidic acid in contrast to C. elegans which targeted ring B in our previous work [17].

Supplementary Materials: The following are available online. Figures S1-S26 are NMR and mass spectra of the isolated compounds. Excel sheets contain the NMR (proton and carbon) calculation results.

Acknowledgments: We are grateful for OpenEye Scientific Software for supporting the academic license. We also thank Ahmed Galal for his help in HR-ESIFTMS analysis of the isolated metabolites at the School of Pharmacy, University of Mississippi, USA.

Author Contributions: A.-R.S.I., K.M.E. and A.E.R. designed and performed research, A.-R.S.I., K.M.E., A.E.R. and D.F. analyzed data, A.-R.S.I., K.M.E., A.E.R. and D.F. wrote and revised the paper.

Conflicts of Interest: The authors declare no conflict of interest.

\section{References}

1. Godtfredsen, W.O.; Jahnssen, S.; Lorck, H.; Roholt, K.; Tybring, L. Fusidic acid: A new antibiotic. Nature 1962, 10, 193-897. [CrossRef]

2. Godtfredsen, W.O.; Vangedal, S. The structure of fusidic acid. Tetrahedron 1962, 18, 1029-1048. [CrossRef]

3. Turnridge, J. Fusidic acid pharmacology, pharmacokinetics, and pharmacodynamics. Int. J. Antimicrob. Agents 1999, 12, S23-S34. [CrossRef] 
4. Collignon, P.; Turnidge, J. Fusidic acid in vitro activity. Int. J. Antimicrob. Agents 1999, 12, S45-S58. [CrossRef]

5. Berchtold, H.; Reshetinova, L.; Reiser, O.A.; Schirmer, N.K.; Sprinzl, M.; Hilgenfeld, R. Crystal structure of the active elongation factor Tu reveals major domain rearrangements. Nature 1993, 365, 126-132. [CrossRef] [PubMed]

6. Reeves, D.S. The pharmacokinetics of fusidic acid. J. Antimicrob. Chemother. 1987, 20, 467-476. [CrossRef] [PubMed]

7. Godtfredsen, W.O.; Vangedal, S. On the metabolism of fusidic acid in man. Acta Chem. Scand. 1966, 20, 1599-1607. [CrossRef] [PubMed]

8. Hadara, K.; Tomita, K.; Fujii, K.; Sato, N.; Uchida, H.; Yazawa, K.; Mikami, Y. Inactivation of fusidic acid by pathogenic Nocardia. J. Antibiot. 1999, 52, 335-339. [CrossRef]

9. Von Daehne, W.; Lorch, H.; Godtfredsen, W.O. Microbial transformation of fusidane-type antibiotics, A correlation between fusidic acid and and helvolic acid. Tetrahedron Lett. 1968, 47, 4843-4846. [CrossRef]

10. Dvnoch, W.; Greenspan, G.; Alburn, H.E. Microbiological oxidation of fusidic acid. Experientia 1966, $22,517$. [CrossRef]

11. Von der Harr, B.; Schrefmp, H. Purification and characterization of a novel extracellular Streptomyces lividans 66 enzyme inactivating fusidic acid. J. Bacteriol. 1995, 177, 152-155. [CrossRef]

12. Evans, L.; Hedger, J.N.; Brayford, D.; Stavri, M.; Smith, E.; O’Donnell, G.; Gray, A.I.; Griffith, G.W.; Simmon, G. Antibacterial hydroxy fusidic acid analogue from Acremonium crotocinigenum. Phytochemistry 2006, 67, 2110-2114. [CrossRef] [PubMed]

13. Yang, W.; Jiang, T.; Acosta, D.; Davis, P.J. Microbial models of mammalian metabolism: Involvement of cytochrome $\mathrm{P} 450$ in the $\mathrm{N}$-demethylation of $\mathrm{N}$-methylcarbazole by Cunninghamella echinulata. Xenobiotica 1993, 23, 973-982. [CrossRef] [PubMed]

14. Rastrup-Andersen, N.; Duvold, T. Reassignment of the ${ }^{1} \mathrm{H}-\mathrm{NMR}$ spectrum of fusidic acid and total assignment of ${ }^{1} \mathrm{H}$ and ${ }^{13} \mathrm{C}-\mathrm{NMR}$ spectra of some selected fusidane derivatives. Mag. Res. Chem. 2002, 40, 471-473. [CrossRef]

15. Von Daehne, W.; Godtfredsen, W.O.; Rasmussen, P.R. Structure-activity relationships in fusidic acid-type antibiotics. Adv. Appl. Microbiol. 1979, 25, 95-145. [PubMed]

16. Galal, A.M.; Ibrahim, A.S.; Mossa, J.S.; El-Feraly, F.S. Microbial transformation of parthenolide. Phytochemistry 1999, 51, 761-765. [CrossRef]

17. Ibrahim, A.S.; Ragab, A.E. Fusidic acid ring B hydroxylation by Cunninghamella elegans. Phytochem. Lett. 2018, 25, 86-89. [CrossRef]

Sample Availability: Samples of the compounds are not available from the authors.

(C) 2018 by the authors. Licensee MDPI, Basel, Switzerland. This article is an open access article distributed under the terms and conditions of the Creative Commons Attribution (CC BY) license (http:/ / creativecommons.org/licenses/by/4.0/). 